\title{
Martine Renouprez (a cura di), L'érotisme
}

\section{Dina Catenaro Catenaro}

\section{OpenEdition}

\section{Journals}

\section{Edizione digitale}

URL: https://journals.openedition.org/studifrancesi/4836

DOI: $10.4000 /$ studifrancesi.4836

ISSN: 2421-5856

\section{Editore}

Rosenberg \& Sellier

\section{Edizione cartacea}

Data di pubblicazione: 1 avril 2012

Paginazione: 192-193

ISSN: 0039-2944

\section{Notizia bibliografica digitale}

Dina Catenaro Catenaro, «Martine Renouprez (a cura di), L'érotisme», Studi Francesi [Online], 166 (I |

LVI) | 2012, online dal 30 novembre 2015, consultato il 19 novembre 2021. URL: http://

journals.openedition.org/studifrancesi/4836 ; DOI: https://doi.org/10.4000/studifrancesi.4836

Questo documento è stato generato automaticamente il 19 novembre 2021.

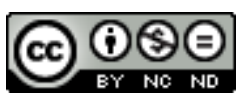

Studi Francesi è distribuita con Licenza Creative Commons Attribuzione - Non commerciale - Non opere derivate 4.0 Internazionale. 


\title{
Martine Renouprez (a cura di), L'érotisme
}

\author{
Dina Catenaro Catenaro
}

\section{NOTIZIA}

MARTINE RENOUPREZ (a cura di), L'érotisme, «Francofonía», 19, 2010, pp. 257.

1 I saggi contenuti nel presente numero della rivista spagnola «Francofonía», interamente consacrato allo studio della rappresentazione del corpo e alla scrittura del desiderio nella narrativa francofona contemporanea, forniscono un quadro dettagliato delle molteplici interpretazioni alle quali si presta la cosiddetta letteratura erotica femminile. Tale campo di indagine si intreccia a tematiche di grande attualità quali la sessualità delle donne nelle società arabo-musulmane e la letteratura dell'emigrazione: l'articolo di Isabelle CHARPENTIER (Amande amère: obsession de la virginité, violence, érotisme et stéréotypes dans les 'contes intimes' "L'Amande" et "La Traversée des sens" de Nedjma, pp. 8-31) ne è il primo esempio. La studiosa si sofferma nello specifico sul dibattito nato attorno alla pubblicazione nel 2004 e nel 2009 di due récits intimes (L'Amande e La Traversée des sens) scritti da una donna di origini marocchine che ha scelto, per motivi di sicurezza, di non rivelare la propria identità, firmandosi con lo pseudonimo di Nedjma, nome simbolico che rinvia al titolo del primo romanzo di Kateb Yacine e, allo stesso tempo, ad una figura mitica della poesia algerina. Charpentier analizza i racconti di Nedjma cercando di mettere in evidenza il ruolo svolto dalla rappresentazione della verginità, strumento attraverso il quale la scrittrice rimette in questione, come afferma la studiosa, «les rapports sociaux de sexe en général, et les constructions sociales de la sexualité féminine en particulier dans un système androcentré» (p. 13). I due racconti nei quali violenza ed erotismo si confondono non possono tuttavia essere eretti a documenti etnografici sulla condizione femminile in Marocco: per meglio comprendere le conseguenze di quello che può essere considerato un atto di denuncia (non privo di ambiguità) da parte di Nedjma, Charpentier ritiene necessario un approfondimento 
della ricezione di queste opere nei paesi musulmani al fine di comprendere meglio l'intento della scrittrice, spesso accusata di opportunismo editoriale.

Dal contesto marocchino si passa a quello belga con lo studio di Nathalie DELGLEIZE ("Karl et Lola" de Caroline Lamarche: fracasser l'inaccessible complétude, pp. 32-47) consacrato all'analisi di uno dei romanzi più recenti di Caroline Lamarche. Pubblicato nel 2007, Karl et Lola affronta il tema scottante del legame incestuoso tra fratello e sorella. Delgleize analizza le molteplici forme della sessualità presenti nel testo, aspetti che non si materializzano attraverso l'evocazione di scene erotiche conclamate ma che si celano dietro atti simbolici, metafore, sguardi. È soprattutto attraverso lo strumento della fotografia che l'esperienza erotica raggiunge il suo apice: «Photographiant Lola, Karl la réduit, la fige, la possède» (p.40), un atto che sembra richiamare quel processo di morte simbolica teorizzato da Roland Barthes ne La chambre claire. L'oggetto di studio si sposta dal campo visivo a quello linguistico attraverso l'articolo di Jamal EL QASRI (Tahar Ben Jelloun: les mots du corps, pp. 48-69) che mette in evidenza la stretta relazione che intercorre nelle opere di Tahar Ben Jelloun tra il corpo femminile e gli elementi del linguaggio. Come sottolinea a più riprese lo studioso, l'onnipresenza di una sessualità spesso cruda che campeggia nei testi dello scrittore marocchino risponde non solo all'esigenza di rappresentare quella realtà di violenza che caratterizza la società maghrebina, ma anche al piacere che l'autore prova nel parlare del corpo: «le corps se révèle non seulement comme un objet ou sujet de désir; il est aussi et surtout stimulus à la créativité et à la célébration langagières» (p. 59).

La letteratura erotica, spesso volgarizzata e disprezzata, può avere dei legami molto stretti anche con un genere letterario come l'«essai»: questa è la tesi sostenuta da Cecilia FERNÁNDEZ SANTOMÉ (L'essai corporalisé ou l'érotisation de la réflexion par Claire Lejeune, pp. 70-83) che ha dimostrato come la scrittrice belga Claire Lejeune si sia a lungo prodigata in un lavoro di ibridazione tra la poesia e il sapere filosofico, dando vita ad una serie di saggi considerati come «le noyau central de sa production intellectuelle» (p.74). Grazie alla stretta collaborazione con gruppi femministi quebecchesi, Lejeune ha associato ad una scrittura filosofica, diretta erede di una tradizione di stampo maschile, una scrittura engagée che ruota attorno a riflessioni sulla condizione femminile e all'interno della quale il tema della riappropriazione del corpo riveste un peso determinante. L'autodeterminazione della propria sessualità può esprimersi anche attraverso pratiche sociali che tendono canonicamente ad affidare alle donne un ruolo passivo: è il caso della poligamia che nel romanzo della scrittrice africana Ken Bugul, Riwan ou le chemin de sable (1999), assume delle connotazioni positive. Nel saggio Musc, petit pagne, et polygamie... (pp. 85-97) la studiosa Esther GONZÁlES ALARCón mette in evidenza come l'opera di Bugul, basata su un'esperienza personale della scrittrice, sia un inno all'erotismo e alla sensualità femminile. La poligamia diventa per Bugul un «havre de paix, creuset du sexe et lieu d'apaisement» (p. 96) che si allontana dai codici sessuali spesso imposti dal mondo occidentale.

4 L'articolo di Catherine GRAVET (Parisiennes, piquantes ou poivrées: les nouvelles de Jeanne Thilda, pp.98-121) fa un salto nel tempo e volge momentaneamente lo sguardo alla letteratura erotica del XIX secolo soffermandosi in particolar modo attorno al 1883, anno della pubblicazione della raccolta Pour se damner della scrittrice belga Jeanne Thilda. Dopo aver ripercorso la biografia dell'autrice, molto conosciuta negli ambienti intellettuali dell'epoca, e ricostruito la genesi editoriale della sua raccolta di nouvelles, Gravet evidenzia l'aspetto irriverente e anticonformista dell'opera nella quale i 
personaggi femminili si liberano dal giogo maschile attraverso la loro carica erotica. L'arte della provocazione caratterizza anche la scrittura di Calixthe Beyala, della quale Daniel S. LARANGÉ approfondisce non soltanto l'aspetto letterario ma anche quello sociale. La scrittrice, afferma Larangé, «détourne texte et conventions afin de dévoiler l'hypocrisie et les supercheries de la modernité» (p. 123), e si prefigge di denunciare la crisi che colpisce il mondo moderno nel quale l'amore spirituale è soppiantato da una sessualità corrotta. L'opera di Beyala appare ancor più scandalosa a causa della scelta effettuata dalla scrittrice di abbinare il discorso erotico a quello mistico, dando luogo ad una forma narrativa nella quale sessualità e sacrificio appaiono strettamente legati.

Il saggio di Georges LEBOUC (Érotisme et linguistique, pp. 144-157) si concentra sullo studio delle contaminazioni con la lingua inglese in molti paesi francofoni, nello specifico il Québec. Lo studioso mette in evidenza come in molte di queste aree si sia deciso di adottare un uso massiccio di anglicismi per evocare le «choses de l'amour» (p. 145) e riconduce questa scelta di ibridazione linguistica alla necessità di esprimersi in una forma «politiquement correct[e]» (p. 152) che permetta di parlare dell'erotismo senza scivolare in situazioni di imbarazzo. Nell'articolo «Le corsage de Milady»: désir et tabou dans "Avant et après" de Jacqueline Harpman (pp. 158-174), la studiosa Francisca ROMERAL ROSEL ha scelto di analizzare i racconti della scrittrice belga Jacqueline Harpman che ha messo a nudo alcuni prototipi della cultura occidentale, evidenziando i condizionamenti delle norme sociali che sostengono i rapporti tra gli esseri umani. Il tabù che Harpman si prefigge di smascherare è quello dei rapporti fugaci che si reggono su uno scambio economico, fatto ancor più scandaloso se a compierlo è una donna anziana che decide di pagare un ventiseienne per ottenere dei favori sessuali: è quello che la scrittrice narra in Avant, in cui il giovane amante tenta di far cadere le reticenze manifestate dalla donna nel momento del fatidico incontro. Romeral Rosel sottolinea l'umorismo della scrittrice che, attraverso una buona dose di ironia, riflette sui meccanismi dell'oppressione morale.

6 Si segnalano infine, fuori dossier, gli inediti di Marianne BASTOGNE (Gratte-moi l'os, pp. 176-178) e di Serge Delaive (Londres, pp. 179-190) e saggi di René godenNe (Les nouvelles «fantastiques» et les nouvelles-nouvelles de Gaston Compère (1924-2008), pp. 192-211) e di Ladislas NZESSÉ (Mode de fonctionnement de l'énonciation et modélisation du réel dans “Contours du jour qui vient" de Léonora Miano, pp. 212-235). 